Research Paper

\title{
Juniperus indica Bertol. extract synergized with cisplatin against melanoma cells via the suppression of AKT/mTOR and MAPK signaling and induction of cell apoptosis
}

\author{
Xiao-Fan Huang1,2\#, Hong-Wei Gao ${ }^{3 \#, ~ S h a n-C h i h ~ L e e ~}{ }^{4,5}$, Kai-Fu Chang1,2, Li-Ting Tang2, Nu-Man Tsai2,6凶 \\ 1. Institute of Medicine, Chung Shan Medical University, Taichung, 40201, Taiwan, ROC. \\ 2. Department of Medical Laboratory and Biotechnology, Chung Shan Medical University, Taichung, 40201, Taiwan, ROC \\ 3. Department of Pathology, Tri-Service General Hospital, National Defense Medical Center, Taipei, 11490, Taiwan, ROC. \\ 4. Department of Medical Imaging and Radiological Sciences, Chung Shan Medical University, Taichung, 40201, Taiwan, ROC. \\ 5. Department of Medical Imaging, Chung Shan Medical University Hospital, Taichung, 40201, Taiwan, ROC. \\ 6. Clinical Laboratory, Chung Shan Medical University Hospital, Taichung, 40201, Taiwan, ROC. \\ \#These authors contributed equally to this work. \\ $\triangle$ Corresponding author: Nu-Man Tsai, PhD, Associate Professor. Department of Medical Laboratory and Biotechnology, Chung Shan Medical University, Tel: \\ 886-4-24730022 ext. 12411; Fax: 886-4-23248171; E-mail: numan@csmu.edu.tw. \\ (C) The author(s). This is an open access article distributed under the terms of the Creative Commons Attribution License (https://creativecommons.org/licenses/by/4.0/). \\ See http://ivyspring.com/terms for full terms and conditions.
}

Received: 2020.06.12; Accepted: 2020.10.15; Published: 2021.01.01

\begin{abstract}
Juniperus indica Bertol. is an herbal plant that belongs to the genus Juniperus, which is commonly used in traditional medicine to refresh the mind and for diuretic use. However, few studies have reported the function of $J$. indica Bertol. Hence, this study aimed to investigate the anti-tumor and synergistic potential of $J$. indica Bertol. extract (JIB extract) for melanoma cells. Our results indicated the anti-melanoma activity of JIB extract. JIB extract induced cell cycle arrest at the $\mathrm{G}_{0} / \mathrm{G}_{1}$ phase and decreased cyclin and cdk protein expressions. In addition, AKT/mTOR signaling and MAPK signaling were inhibited by JIB extract to suppress melanoma cell growth and proliferation. Additionally, JIB extract induced B16/F10 cell apoptosis via the caspase cascade. According to the JIB extract's anti-melanoma capacity, to assess the synergistic effects of cisplatin and JIB extract. The results demonstrated that JIB extract combined with cisplatin enhanced the inhibition of cell growth, proliferation, and survival through the obstruction of cell cycle progression and AKT/mTOR and MAPK signaling as well as the induction of cell apoptosis. Collectively, our results indicate that JIB extract showed anti-tumor effects and synergized with cisplatin against B16/F10 cells, indicating the possibility of JIB extract to be developed as adjuvant therapy for melanoma.
\end{abstract}

Key words: melanoma, Juniperus indica Bertol., synergism, cisplatin, anti-proliferation

\section{Introduction}

Melanoma is the most malignant and lethal skin tumor owing to its high metastatic ability and the incidence of melanoma has been increasing over the years. The survival rate of melanoma patients with increasing stage ranges from $85 \%$ to $25 \%$ due to the high incidence of metastasis [1]. The current treatments for melanoma are surgery, which is performed in the early stages of the disease, and neoadjuvant treatments for advanced patients, including chemotherapy, radiotherapy, targeted therapy, immunotherapy and combination therapy [2, 3]. Among these, targeted therapy and immunotherapy are now the current main therapeutic procedure in melanoma. Targeted therapy drugs are used to target specific genes and proteins of cancer cells to precisely identify and attack specific types of cancer cells. Some studies revealed the rate of BRAF mutation is about $15-25 \%$ in Asian, which is significantly lower than that in Caucasians (50\%-70\%) [4]. For instance, vemurafenib is a targeted therapy for melanoma with BRAF gene mutation. It can reduce the disease progression rate by $74 \%$ and improves outcomes for patients; however, about half of the patients will relapse again after five to six months [5]. Besides, $12 \%$ of patients have second- or third-degree skin reactions that are sensitive to light, and about 
$18 \%$ of patients develop cutaneous squamous-cell carcinoma and keratoacanthoma or occurred at the same time [6]. Immunotherapy helps to activate the immune system to fight cancer. For example, nivolumab is a monoclonal antibody and immune checkpoint inhibitors. It can target PD- 1 in T cells to help $\mathrm{T}$ cells to recognize cancer cells and kill them through an immune response. The response rate is $32 \%$, and the therapeutic effect only sustains six months. It can induce a severe immune reaction, hypofunction of thyroid glands, adrenal insufficiency, nephritis, and increment of the liver index [7]. Ipilimumab is an immune checkpoint inhibitor that can inhibit CTLA-4 on human T cells to activate the immune system and attack cancer cells to achieve the effect of treating cancer. The response rate to melanoma was only about $10 \%$, and only $20 \%$ of patients can achieve long-term survival [8]. Pembrolizumab immune checkpoint inhibitor against PD-1. The response rate is $30 \%$, which is better than ipilimumab. The side effects of pembrolizumab are similar to ipilimumab, including skin rash, diarrhea, abnormal liver function, and hypofunction of endocrine system function [9]. Nivolumab, ipilimumab, and pembrolizumab are immune checkpoint inhibitors and can cause immunemediated pneumonitis, colitis, hepatitis, and endocrinopathies nephritis, skin adverse reactions, encephalitis.

With recent advances in immunotherapy and targeted therapy which has improved the median OS for advanced melanoma, however, chemotherapy is also the backbone of systemic treatment for advanced melanoma for many years [10]. Besides, in Taiwan, the use of target and immunotherapy is still very restricted. The first reason is that the most common melanoma in Taiwan is acral lentiginous melanoma, which is different from Western countries. The second reason is that less than $20 \%$ of patients in Taiwan have BRAF mutations, and patients who received targeted therapy will gradually develop resistance after one year. Therefore, most patients cannot benefit from targeted drug treatment. Moreover, although immunotherapy is not limited to specific gene mutations, its expensive medicines are not affordable by the general public. For the above reasons, most of the treatments for metastatic melanoma in Taiwan are still based on traditional combined chemotherapy. For example, platinum-based chemotherapy drugs, such as cisplatin, carboplatin, paclitaxel, or dacarbazine (DITC). Cisplatin is used as a chemotherapeutic agent for the treatment of several cancers and is commonly applied for neoadjuvant or adjuvant therapy at different stages of cancer therapy. In addition, many clinical trials have used cisplatin in the treatment of melanoma [11, 12]. Cisplatin- paclitaxel -dacarbazine regimen has shown that the response rate of $41 \%$ and the median overall survival time is 11 months [13]. Carboplatin plus paclitaxel has revealed that the median progression-free survival is 4.2 to 4.4 months, and the median overall survival time 9 to 11 months [14]. These chemo-drugs may also cause nephrontoxicity, ototoxicity, neurotoxicity, cardiotoxicity, hepatotoxicity, hematological toxicities, and gastrointestinal toxicity. Hence, these anticancer agents provide good survival benefits for patients and cause different side effects during the therapeutic procedure. It is hoped to find new combined chemotherapy drugs with low physiological toxicity to reduce side effects and overcome the current limitations of use and be widely used clinically, thereby bringing patients' most tremendous benefits.

The natural product is the primary source of the development of drugs, and several current compounds have been used as a standard therapeutic drug on the various treatment of disease. Moreover, natural extracts exert several bio-functions all in one, such as anticancer, anti-inflammatory, antioxidative activity. Besides, natural extracts not only have been reported its' anticancer activity in several types of plants but also demonstrated its' effects on reducing the side effects in the therapeutic procedure. For instance, Bacopa monnieri extract may be useful alone or in combination with other anti-emetic drugs to treat cisplatin-induced emesis in man [15]. Nigella sativa oil ameliorates the effect of cisplatin-induced gastrointestinal dysfunction [16]. Juniperus indica Bertol. is an evergreen tree that is distributed in high-altitude regions with low temperatures $[17,18]$. A few scientific studies have reported on the use of $J$. indica Bertol. It has been found to have anti-microbial and cytotoxic activities [19]. Nevertheless, J. communis which is classified to Juniperus genus and is the same genus but different species as J. indica Bertol. have fully investigated several bio-functions. For example, J. communis exhibits hepatoprotective potential against paracetamol and azithromycin induced liver injury in rats [20], ameliorates tacrolimus-induced nephrotoxicity in rats [21], exerts anti-hypoglycemic and anti-hypolipidemic effects in alloxan-induced diabetic rats [22], and treats the neurasthenic neurosis, and against Freund's adjuvantinduced arthritis in rats [23]. However, the biofunctions of J. indica Bertol. (JIB extract) have not been fully explored. Here, we aimed to investigate the synergistic effects of JIB extract combined with cisplatin on melanoma to reduce the cisplatin concentration to prevent the unpredictive clinical outcome. 
In our study, JIB extract significantly inhibited B16/F10 cell growth and impeded cell cycle at $G_{0} / G_{1}$ phase and triggered cell death through apoptosis. Furthermore, JIB extract combined with cisplatin has synergistic effects on the enhancement of cell repression, induction of cell apoptosis, interruption of AKT/mTOR signaling, and MAPK signaling. Consequently, JIB extract can be potentially utilized as an anti-melanoma agent and adjuvant treatment in the future and this study might provide a new therapeutic strategy for patients who do not have BRAF mutations and cannot receive immunotherapy.

\section{Materials and methods}

\section{Cell culture}

The B16/F10 (Mouse skin melanoma) and MDCK (Canine kidney epithelial cell) cell lines were purchased from the Bioresource Collection and Research Center (Hsinchu, Taiwan). MDCK cell line was used as an example for kidney toxicity assay in this study. Both cell lines were cultured in DMEM medium supplemented with $10 \%$ FBS, $1 \%$ sodium pyruvate, $1 \%$ HEPES, and $1 \%$ penicillin/streptomycin in a humidified incubator with $5 \% \mathrm{CO}_{2}$. Cells were sub-cultured with $0.05 \%$ trypsin-EDTA for the follow-up experiment. All cell culture reagents were purchased from Gibco (Grand Island, NY, USA).

\section{Preparation of Juniperus indica Bertol. extract (JIB extract)}

A fresh Juniperus indica Bertol. plant from Nepal was utilized, and the extract was obtained by steam distillation. The small-scale extraction was done in our lab and the detailed conditions were described as the following. The fresh fruits of Juniperus indica Bertol. (400g) were placed in a 2-L steam distillation steel apparatus unit and the generated steam passed through plant material for $100 \mathrm{mins}$ at $100 \sim 105^{\circ} \mathrm{C}$ and a flow rate of approximately $7.2 \mathrm{ml} / \mathrm{min}$. The large scale of JIB extract was commissioned by Phoenix (New Jersey, USA). The JIB extract was preserved in an airtight and lightproof aluminum can and stored at $4^{\circ} \mathrm{C}$. Before conducting the experiments, the JIB extract was dissolved in DMSO and measured in $\mu \mathrm{g} / \mathrm{ml}$. The concentration of JIB extract $=$ the weight of $20 \mu \mathrm{lJB}$ extract (g)/ (the weight of $180 \mu \mathrm{l}$ DMSO + the weight of $20 \mu \mathrm{l} \mathrm{JIB} \mathrm{extract)} \mathrm{(g).}$

\section{Cell viability of cells}

Cell viability was assessed by MTT assay. B16/F10 $\left(5 \times 10^{3}\right)$ and MDCK $\left(1 \times 10^{4}\right)$ cells were grown in 96-well plates and treated with JIB extract $(0-100 \mu \mathrm{g} / \mathrm{ml})$, cisplatin $(0-10 \mu \mathrm{g} / \mathrm{ml})$, and 5 -FU $(0-2$ $\mu \mathrm{g} / \mathrm{ml}$ ) for 24, 48, and $72 \mathrm{hrs}$, respectively. After incubating the cells with these drugs, the medium was discarded and replaced with MTT solution (500 $\mu \mathrm{g} / \mathrm{ml}$ ) and incubated for $8 \mathrm{hrs}$. After removing the MTT solution, the crystals were dissolved in DMSO, and the absorbance was measured at $550 \mathrm{~nm}$. The percentage of cell viability was calculated using the following formula: treating/untreated $\times 100 \%$, and the data were presented as mean \pm SD. The experiment was repeated three times under the same conditions.

\section{Synergistic proliferation assay}

Cells $\left(5 \times 10^{3}\right)$ were seeded in 96-well plates and treated with serial concentrations of JIB extract (0-60 $\mu \mathrm{g} / \mathrm{ml})$ and cisplatin $(0-4 \mu \mathrm{g} / \mathrm{ml})$. Cell viability inhibition was determined using the MTT assay, and the combination index was calculated using CompuSyn software (ComboSyn, Inc., Paramus, NJ, USA) [24, 25]. Each experiment was carried out in triplicate, independently.

\section{Cell cycle analysis}

B16/F10 cells were seeded in $10 \mathrm{~cm}$ dishes at a density of $1 \times 10^{6}$ cells and cultured for 12-16 hrs in an incubator. After cell fulling to $60 \%-70 \%$ of dishes, the indicating drugs were given to cells for $6,12,24$ and $48 \mathrm{hrs}$. After treatment, the cells were harvested and stained with PI $(40 \mu \mathrm{g} / \mathrm{ml})$ in PBS containing 100 $\mu \mathrm{g} / \mathrm{ml}$ RNase overnight at $4^{\circ} \mathrm{C}$. Cell cycle distribution was evaluated in independent tests for three times. The detailed analyzed method we utilized in this experiment was described as the following. We selected a fixed area of sub- $G_{1}, G_{0} / G_{1}, S$, and $G_{2} / M$ phase in each group. All cells were divided into two groups, and one was the living cell population to establish the purpose of observing drug-induced changes of the cell population in cell cycle distribution. The calculated formula of cell cycle distribution was the indicated cell population $\left(\mathrm{G}_{0} / \mathrm{G}_{1}\right.$, $\mathrm{S}$, or $\mathrm{G}_{2} / \mathrm{M}$ phase) / total alive cells $\times 100 \%$. Another was a dead cell population to evaluate drug-induced cell death. The area of sub- $\mathrm{G}_{1}$ phase was set below 160 of FL2-A and the calculated formula of sub-G $\mathrm{G}_{1}$ phase was sub- $\mathrm{G}_{1}$ cell population / total cell population containing alive and dead cells $\times 100 \%$. Cell cycle distribution was determined using a FACSCalibur (Franklin Lakes, NJ, USA) and analyzed using FlowJo 7.6.1 (Ashland, Oregon, USA).

\section{Western blot}

B16/F10 cells $\left(1 \times 10^{6} /\right.$ dish $)$ were treated with JIB extract $(30 \mu \mathrm{g} / \mathrm{ml})$, cisplatin $(2 \mu \mathrm{g} / \mathrm{ml})$, and a combination of drugs. After treatment, the cells were harvested and incubated with lysis buffer to collect the total protein extract. Total protein concentration was determined using BCA Protein Assay Reagent (Thermo Fisher Scientific, Waltham, MA, USA). 
Proteins were electrophoretically separated on SDSPAGE and transferred onto PVDF. The membranes were incubated with 5\% skim milk to block nonspecific binding. Primary and secondary antibodies were added to incubate with membranes for the desired temperature and time points, respectively. After washing, the membranes were incubated with horseradish peroxidase and visualized by chemiluminescence (T-Pro LumiFast Plus Chemiluminescence Detection Kit; T-Pro Biotechnology, New Taipei County, Taiwan). Immunolabeled proteins were detected by GE LAS-4000 (Little Chalfont, United Kingdom), and the intensities of stained bands were quantified using the ImageJ software (NIH, Betlesda, MD, USA). Three parallel experiment analyses are carried out. The primary antibodies against ERK, PARP, p21, bax, bcl2, AKT, cyclinB1 and cyclinD1 were purchased from iReal Biotechnology Co., Ltd. (Hsinchu, Taiwan) and the others were purchased from Santa Cruz Biotechnology (California, USA).

\section{Statistical analysis}

Quantitative data were presented as mean \pm SD. Results were statistically analyzed using the Student's $t$-test. A $P$ value of $<0.05$ was considered significant.

A
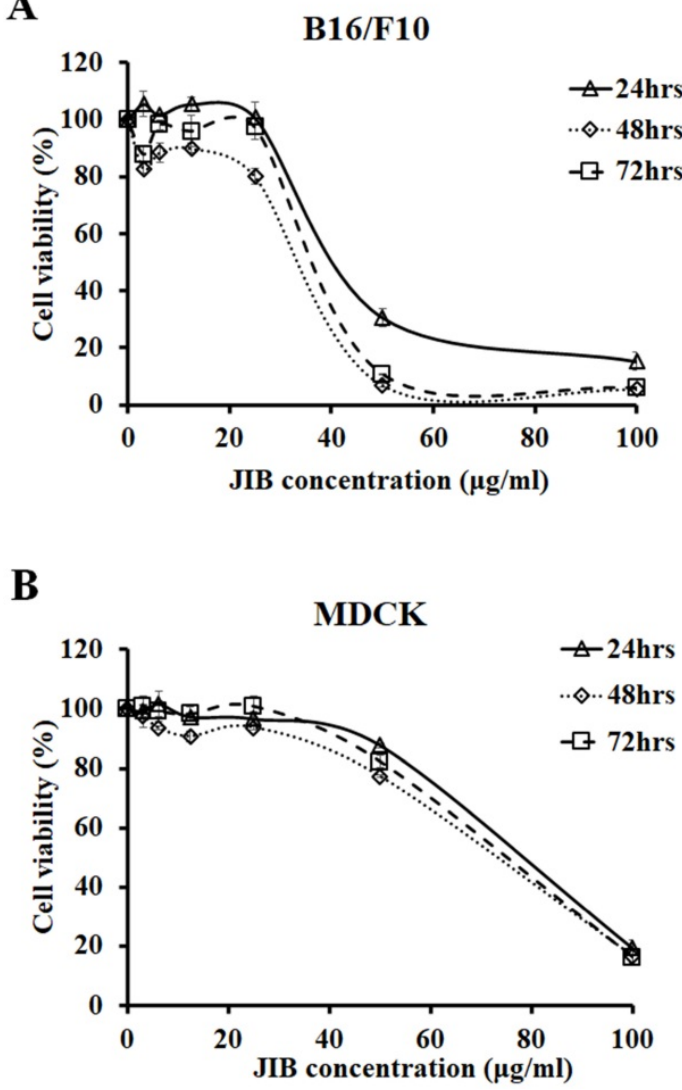

\section{Results}

\section{JIB extract reduced the viability of B $16 / F 10$ cells and affected the MDCK cell growth with less inhibitory effects}

To examine the inhibitory effect of JIB extract on B16/F10 cells, B16/F10 cells were treated with serial concentrations of JIB extract for the indicated time, and the MTT assay was performed. The cell viability of B16/F10 cells was reduced from $100 \%$ to $15.22 \pm$ $3.28 \%, 5.43 \pm 0.16 \%$, and $5.86 \pm 0.25 \%$ after treatment with $0-100 \mu \mathrm{g} / \mathrm{ml}$ JIB extract for 24,48 , and $72 \mathrm{hrs,}$ respectively. Moreover, 50 and $100 \mu \mathrm{g} / \mathrm{ml}$ of JIB extracts inhibited the cell viability of B16/F10 cells by $69 \%-94 \%$ in a dose-dependent manner (Figure 1A). The JIB extract-treated MDCK cells were further testified and MDCK cells derived from Canine strain were used to evaluate the kidney toxicity in vitro. As shown in Figure 1B, $100 \mu \mathrm{g} / \mathrm{ml} \mathrm{JIB}$ extract strongly inhibited the cell viability of MDCK cells by $80 \%$. However, $50 \mu \mathrm{g} / \mathrm{ml}$ JIB extract inhibited $12 \%-22 \%$ of the MDCK cells. In addition, the $\mathrm{IC}_{50}$ of JIB extract in B16/F10 cells was $43.12 \pm 3.81 \mu \mathrm{g} / \mathrm{ml}$ at $24 \mathrm{hrs}$. Compared with the $\mathrm{IC}_{50}$ of JIB extract, the $\mathrm{IC}_{50}$ value of MDCK cells was $77.48 \pm 1.81 \mu \mathrm{g} / \mathrm{ml}$ at $24 \mathrm{hrs}$ and was

C

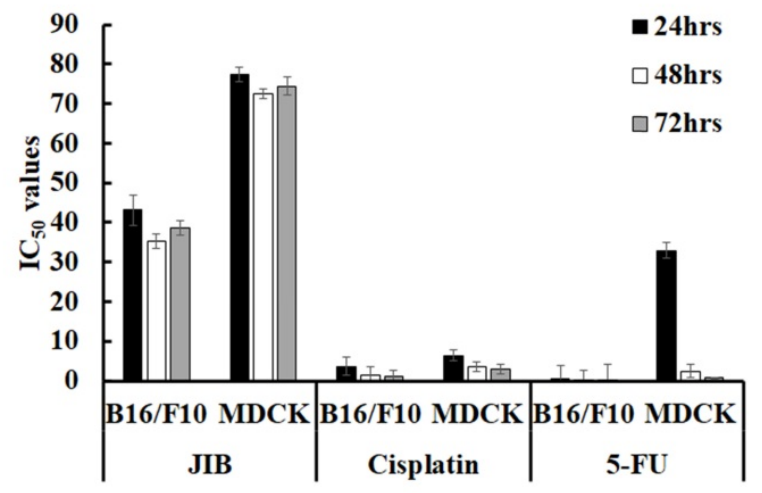

Figure 1. JIB extract inhibited B 16/F10 cells proliferation and had a lower inhibitory effect on MDCK cells. B16/F10 $\left(5 \times 10^{3}\right)$ and MDCK $\left(1 \times 10^{4}\right)$ cells were seeded in 96 -well plates and treated with JIB extract $(0-100 \mu \mathrm{g} / \mathrm{ml})$ for 24,48 , and $72 \mathrm{hrs}$. Cell viability was determined as a percentage and was evaluated by the MTT assay. (A,B) Growth inhibition of B16/F10 and MDCK cells. (C) The IC 50 of B16/F10 and MDCK cells were treated with JIB extract, cisplatin, or 5-FU for 24, 48, and 72 hrs. 
approximately 2-fold higher than the $\mathrm{IC}_{50}$ of B16/F10 cells (Figure 1C). These results revealed that JIB extract at concentrations of 50 and $100 \mu \mathrm{g} / \mathrm{ml}$ efficiently inhibited B16/F10 cells but not MDCK cells, suggesting that JIB extract might present a good selective ability for tumor cells owing to the significant difference in $\mathrm{IC}_{50}$. Subsequently, the $\mathrm{IC}_{50}$ values of cisplatin and 5-FU, the chemotherapeutic drugs that are commonly used for combination therapy, were determined by the MTT assay. Although cisplatin and 5-FU showed a better inhibitory effect on B16/F10 cells, these chemotherapeutic drugs also exerted strong cytotoxicity against MDCK cells owing to the $\mathrm{IC}_{50}$ of cisplatin and $5-\mathrm{FU}$, showing no obvious difference in both cell types. In summary, JIB extract inhibited B16/F10 cell growth and was less cytotoxic to MDCK cells.

\section{JIB extract plus cisplatin showed a synergistic effect to decrease cell viability in B16/F10 cells}

Cisplatin is utilized as a part of combination therapy to treat melanoma, and the common adverse

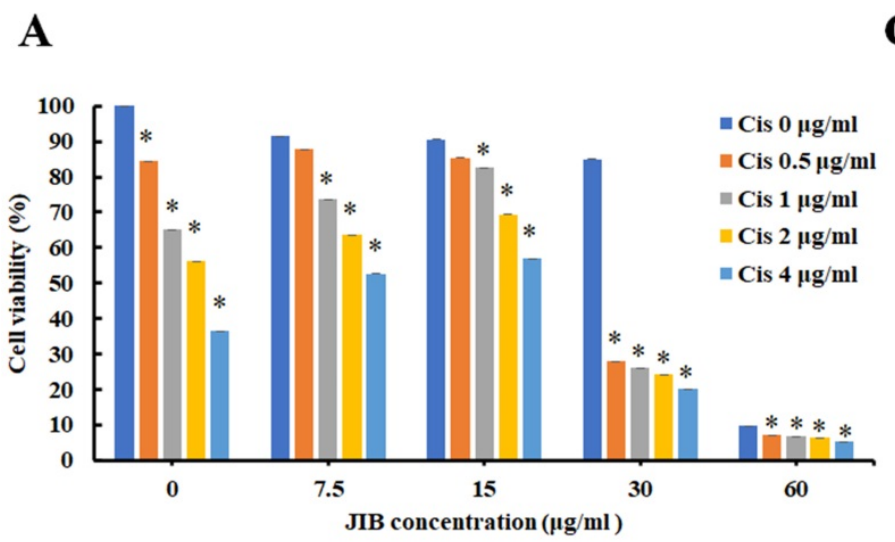

B

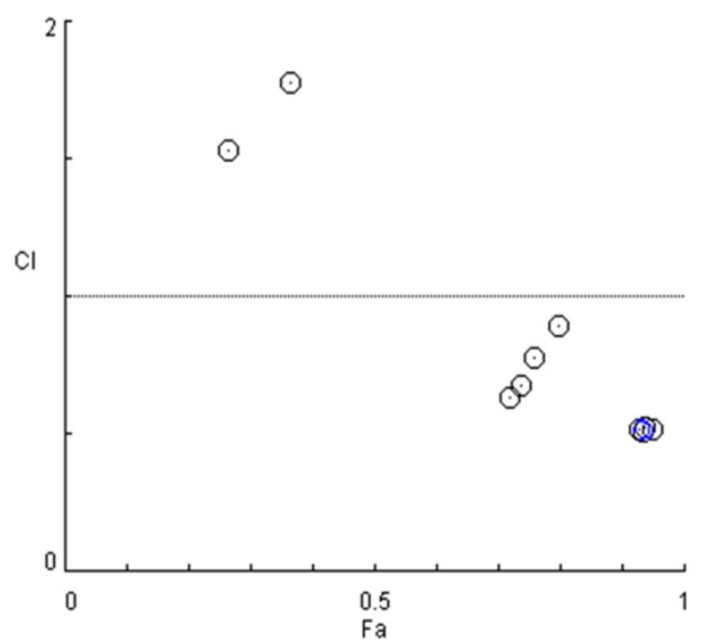

effects are immunosuppression and nephrotoxicity. The former data revealed the anti-melanoma activity of JIB extract. To evaluate the combination index of JIB extract plus cisplatin, the B16/F10 cells were treated with combination treatment for $48 \mathrm{hrs}$. As shown in Figure 2A, cisplatin combined with JIB extract of 7.5 and $15 \mu \mathrm{g} / \mathrm{ml}$ did not definitely reduce cell viability. Nevertheless, when cisplatin $(0.5-4 \mu \mathrm{g} / \mathrm{ml})$ was combined with $30 \mu \mathrm{g} / \mathrm{ml}$ of JIB extract, the cell viability of B16/F10 cells decreased ranged from $67 \%$ to $76 \%$ (Figure 2A). After that, the combination index was calculated using the Comsyn software. The combination index plot and normalized isobologram showed that JIB extract combined with cisplatin had a synergistic effect on the inhibition of B16/F10 cell growth within $48 \mathrm{hrs}$ (Figure 2B and C). In addition, JIB extract concentrations of 30 and $60 \mu \mathrm{g} / \mathrm{ml}$ revealed serial combination index, which was less than 1 , while JIB extract combined with serial cisplatin (Figure 2D). These results demonstrated that JIB extract plus cisplatin exhibited a synergistic effect.

C

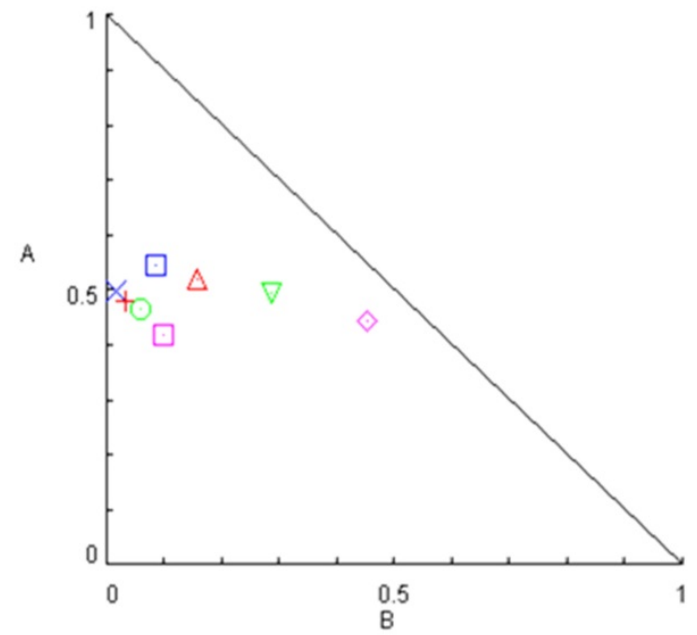

D

\begin{tabular}{|c|c|c|}
\hline $\mathbf{J I B}(\boldsymbol{\mu g} / \mathbf{m l})$ & Cis $(\boldsymbol{\mu g} / \mathbf{m l})$ & CI value \\
\hline 30 & 0.5 & 0.63 \\
\hline 30 & 1.0 & 0.68 \\
\hline 30 & 2.0 & 0.78 \\
\hline 30 & 4.0 & 0.90 \\
\hline 60 & 0.5 & 0.52 \\
\hline 60 & 1.0 & 0.51 \\
\hline 60 & 2.0 & 0.53 \\
\hline 60 & 4.0 & 0.52 \\
\hline
\end{tabular}

Figure 2. JIB extract combined with cisplatin had a synergistic effect on the inhibition of B16/F10 cell growth. B16/F10 cells with a density of $5 \times 10^{3}$ cells were grown in 96 -well plates and treated with JIB extract $(0,7.5,15,30$, and $60 \mu \mathrm{g} / \mathrm{ml})$ and cisplatin $(0,0.5,1,2$, and $4 \mu \mathrm{g} / \mathrm{ml}) \mathrm{for} 48 \mathrm{hrs}$. The synergistic effect was expressed as a percentage of cell viability and evaluated by the MTT assay. (A) The cell viability of JIB extract combined with cisplatin on B16/F10 cells. *: Indicates a significant decrease between untreated and treated groups $(p<0.05)$. (B) Combination index plot. (C) Normalized isobologram for the combination of JIB extract and cisplatin. (D) The table of the combination index. 
A

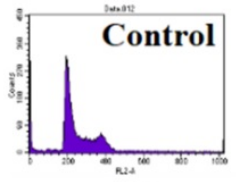

JIB

$(30 \mu \mathrm{g} / \mathrm{mL})$
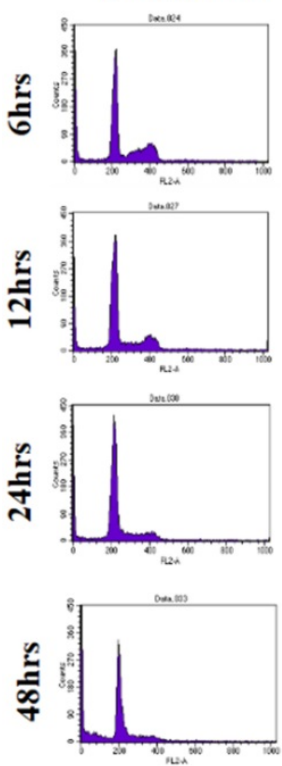

C

\section{Cisplatin}

$(2 \mu \mathrm{g} / \mathrm{mL})$
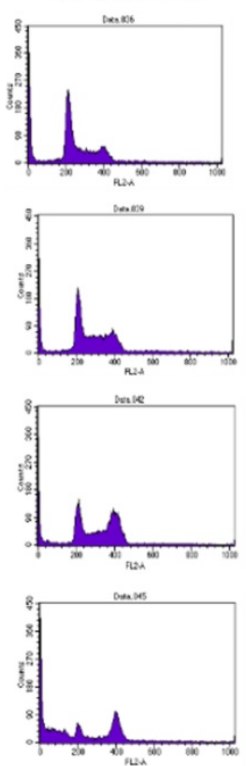

Con Cis JIB C+J
B
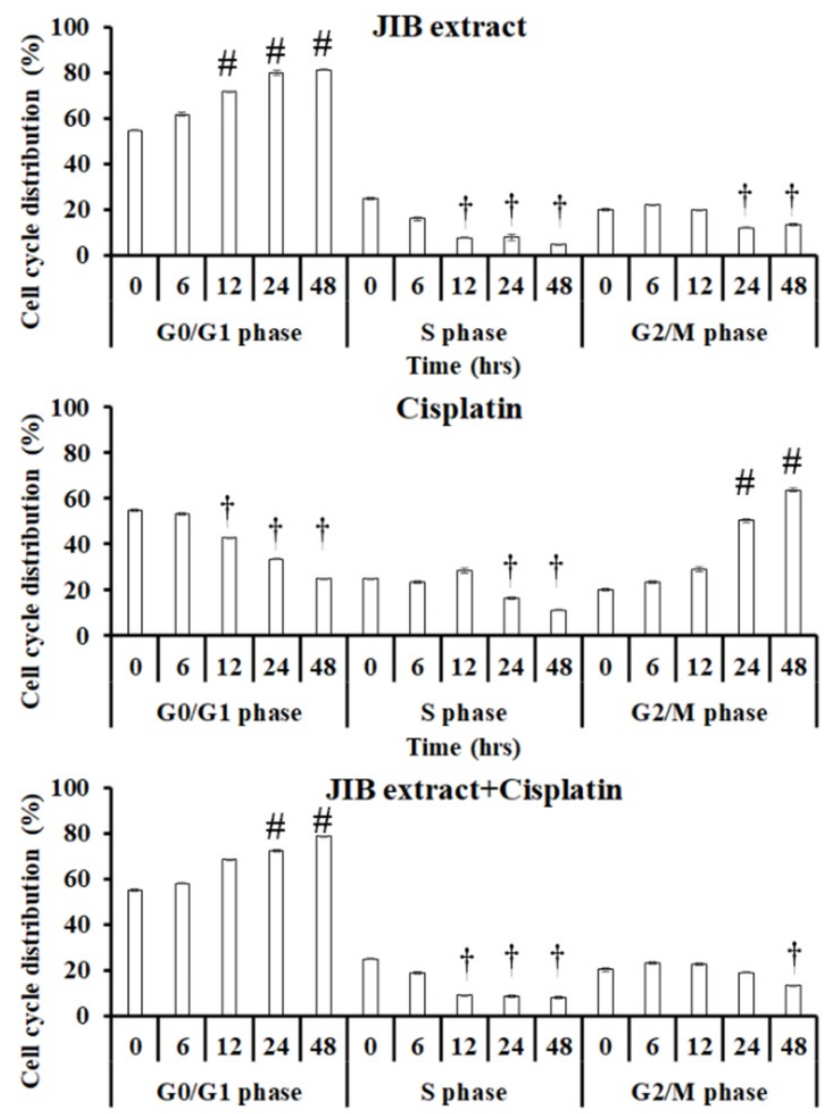

Time (hrs)
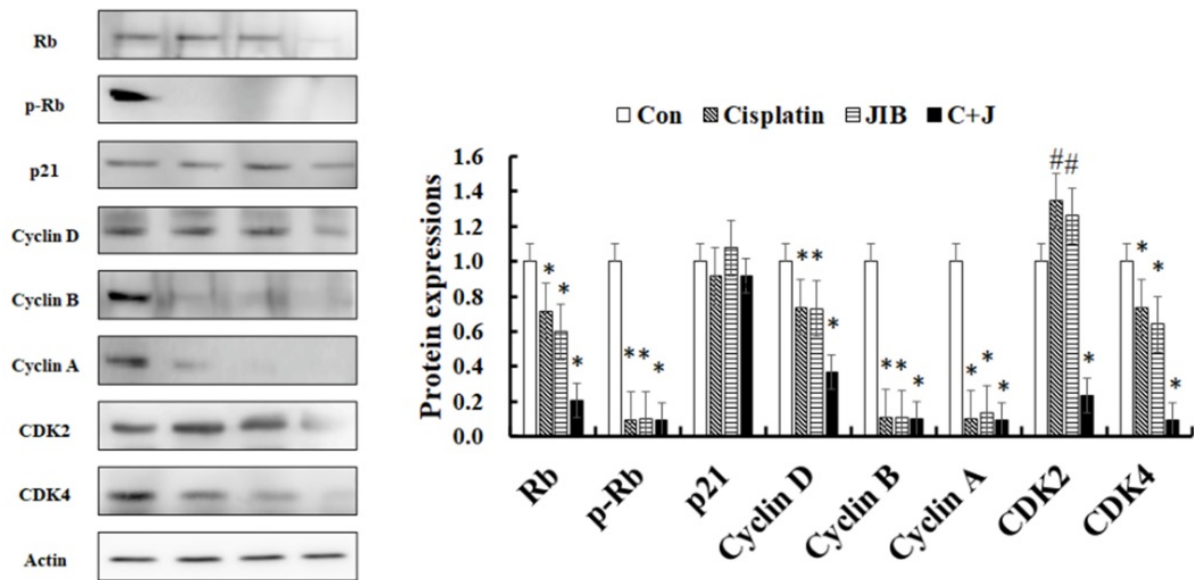

Figure 3. JIB extract synergized with cisplatin to block cell cycle progression at the $\mathbf{G}_{0} / \mathbf{G}_{1}$ phase in $\mathrm{B} 16 / \mathrm{F} 10 \mathrm{cells}$. B16/F10 cells $\left(1 \times 10^{6}\right)$ were seeded in $10 \mathrm{~cm}$ dishes and treated with a combination of JIB extract $(30 \mu \mathrm{g} / \mathrm{ml})$ and cisplatin $(2 \mu \mathrm{g} / \mathrm{ml})$ for $6,12,24$, and 48 hrs. After harvesting cells and staining with PI, the cell cycle progression of B16/F10 cells was analyzed by flow cytometry with the channel at FL2-A (red). (A) Cell cycle distribution plot. (B) The bar of cell cycle distribution on JIB extract, cisplatin, and a combination of JIB extract and cisplatin. \#: It was a significant increase between untreated and treated groups; $t$ : It was a significant decrease between untreated and treated groups $(p<0.05)$. After drug treatments, total proteins were harvested, quantified by the BCA assay, and resolved by Western blotting. (C) The expression of cell cycle-related proteins in B16/F10 cells. C+J: indicated cisplatin treatment plus JIB treatment. *: It was a significant increase between untreated and treated groups; \#: It was a significant decrease between untreated and treated groups $(p<0.05)$.

\section{JIB extract combined with cisplatin to impede cell cycle progression and downregulate cell cycle-related proteins}

Former results indicated that JIB extract combined with cisplatin had a synergistic effect; to examine whether the combination treatment affected the cell cycle distribution of B16/F10 cells, flow cytometry was conducted. JIB extract, cisplatin, and combination treatment affected the cell cycle distribution at different time points (Figure 3A). JIB extract induced cell cycle arrest at the $G_{0} / G_{1}$ phase in a time-dependent manner and these values were showed $54.91 \pm 0.39 \%, 61.81 \pm 0.76 \%, 71.94 \pm 0.22 \%$, 
$79.99 \pm 1.23 \%$, and $81.37 \pm 0.43 \%$ corresponding to the indicated time interval and reduced the population in the $S$ phase and $G_{2} / M$ phase, respectively. Cisplatin increased the cell population in the $\mathrm{G}_{2} / \mathrm{M}$ phase within at 24 and $48 \mathrm{hrs}(20.51 \pm 0.69 \%, 23.51 \pm 0.38 \%$, $29.00 \pm 1.18 \%, 50.45 \pm 0.79$, and $63.69 \pm 0.64 \%)$ and decreased the population in the $\mathrm{G}_{0} / \mathrm{G}_{1}$ and $S$ phase. JIB extract synergized with cisplatin to increase cell cycle arrest at the $\mathrm{G}_{0} / \mathrm{G}_{1}$ phase $(54.91 \pm 0.39 \%, 57.84 \pm$ $0.27 \%, 68.36 \pm 0.23 \%, 72.40 \pm 0.40 \%$, and $78.91 \pm 0.07 \%$ ) and reduced the $S$ and $\mathrm{G}_{2} / \mathrm{M}$ cell populations (Figure 3B). These results suggested that JIB extract plus cisplatin increased the majority of the cell population in the $\mathrm{G}_{0} / \mathrm{G}_{1}$ phase to inhibit B16/F10 cell growth. Next, we tested the cell cycle-related proteins that might be regulated by JIB extract plus cisplatin. $\mathrm{Rb}$ binds to the $\mathrm{E} 2 \mathrm{~F}$ factor to block cell cycle progression and phosphorylated $\mathrm{Rb}$ is dissociated with E2F to promote cell proliferation [26]. After treatment with JIB extract or cisplatin, JIB extract plus cisplatin inhibited total $\mathrm{Rb}$ and phosphorylated $\mathrm{Rb}$ expression,

A
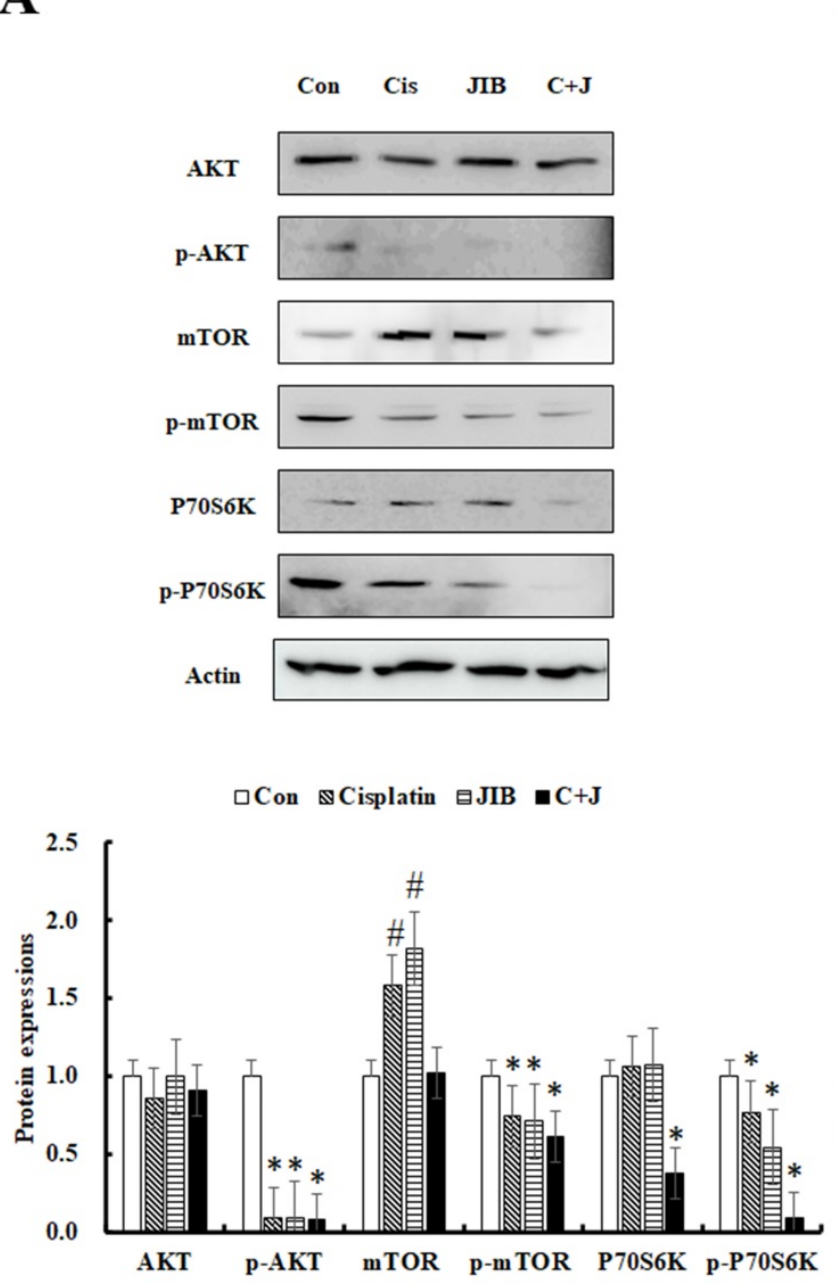

thus reducing cell growth. JIB extract strongly induced p21 protein expression, which resulted in cell cycle arrest. The expression of downstream cell cycle proteins that are regulated by $\mathrm{p} 21$, including cyclins and CDKs were reduced after JIB extract or cisplatin treatment. JIB extract combined with cisplatin enhanced the suppression of cyclins and CDKs protein expressions, especially $\mathrm{Rb}, \mathrm{cdk} 2$, cdk4, and cyclin D (Figure 3C). JIB extract or cisplatin possessed an anti-proliferative ability through the mediation of cell cycle-related proteins to arrest cell cycle progression, and JIB extract plus cisplatin improved the obstruction of cell cycle progression in B16/F10 cells.

\section{JIB extract synergized with cisplatin to inhibit AKT/mTOR signaling}

The AKT/mTOR pathway is known to facilitate cell proliferation and survival in various cancers. Consequently, the AKT/mTOR pathway was further examined. As shown in Figure 4A, the AKT protein
B
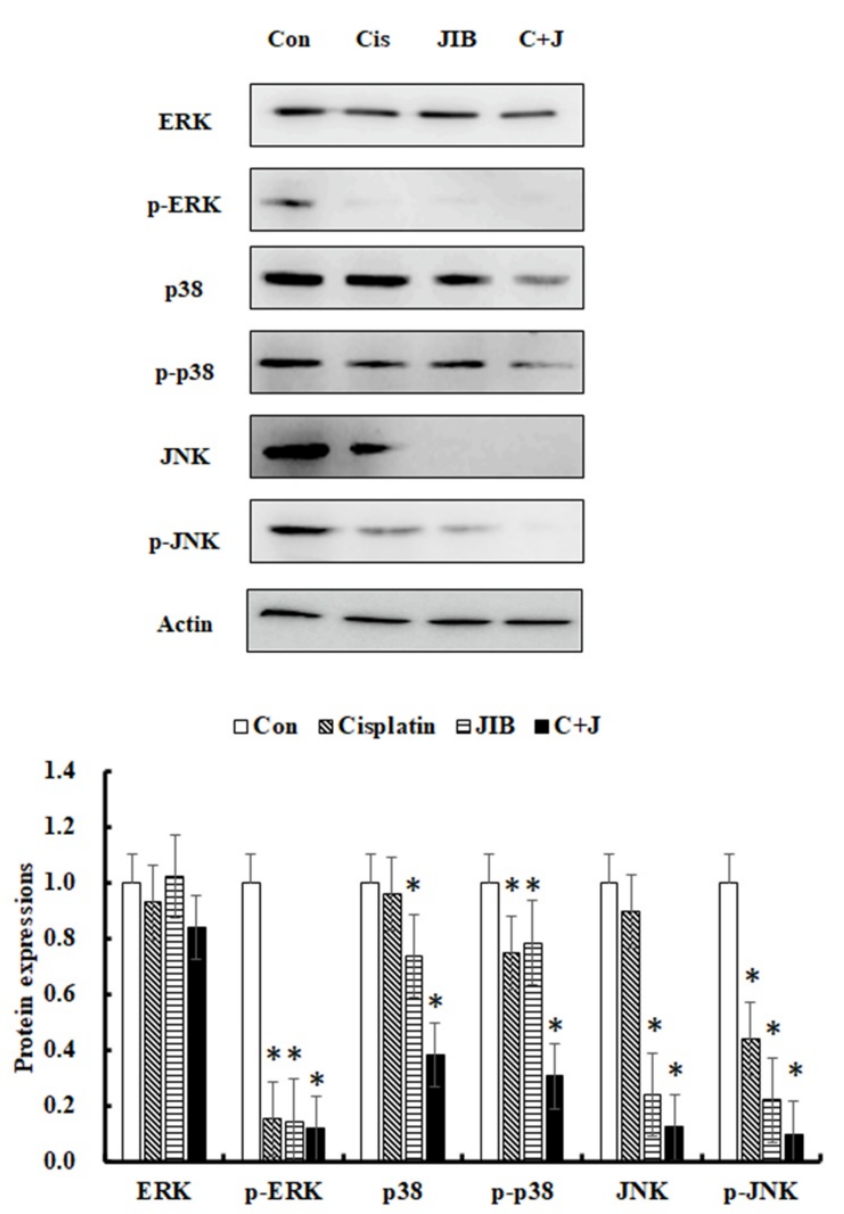

Figure 4. JIB extract synergized with cisplatin to repress cell proliferation and survival pathways in B16/F10 cells. B16/F10 cells were treated with the indicated drugs for $48 \mathrm{hrs}$ and harvested to determine the concentration of total proteins. After that, total proteins were analyzed by Western blotting. $\mathrm{C}+\mathrm{J}$ : indicated cisplatin treatment plus JIB treatment. *: It was a significant decrease between untreated and treated groups; \#: It was a significant increase between untreated and treated groups $(p<0.05)$. 
was not clearly reduced by drug alone or a combination of JIB extract and cisplatin. The expression of p-AKT was markedly inhibited by JIB extract, cisplatin and so as in combination treatment. mTOR and p-mTOR (Ser2448) proteins were strongly decreased by treatment with JIB extract plus cisplatin in comparison with drug alone treatment. Similar results were obtained for the downstream proteins of P70S6Ka and p-P70S6Ka (Ser411), which were strongly repressed by combination treatment compared with either drug alone (Figure 4A). The results indicated that JIB extract combined with cisplatin exerted a synergistic effect to impede the AKT/mTOR pathway, thus inhibiting cell proliferation and growth.

\section{JIB extract synergized with cisplatin to reduce ERK, p38, and JNK signaling}

The MAPK pathway, including ERK, p38, and JNK, was further to examine the changes of protein expressions. ERK signaling plays important roles in regulating cell proliferation, and cell survival [27]; p38 signaling is often activated in advanced-stage melanoma that correlates to metastatic and chemoresistant melanoma [28]; JNK signaling regulates lots of cellular processes, including cell proliferation, differentiation, survival and migration [29]. JIB extract or cisplatin only slightly affected ERK and p38 expression. In contrast, JNK expression was distinctly reduced by JIB extract. The phosphorylation of ERK was repressed by both JIB extract and cisplatin; by contrast, p-p38 and p-JNK were not markedly affected by either of the drugs. The combination of JIB extract and cisplatin predominantly decreased the expression of p-ERK1/2 (Tyr204), p-p38a/ $\beta / \gamma$ (Tyr182), and p-JNK1/2/3 (Thr183/Tyr185) (Figure 4B). Overall, drug alone and combinational treatment significantly interrupted the p-ERK protein expression to suppress B16/F10 cell growth. Besides, p38 signaling was statistical difference inhibited by JIB extract and combinational treatment, suggesting that JIB extract might enhance the anti-melanoma capacity of cisplatin on metastasis and also reduce the potential of chemoresistant in B16/F10 cells. JIB extract alone and its' combinational treatment diminished the JNK signaling in B16/F10 cells to suppress cell proliferation. As a result, the combination of these two drugs strengthened the inhibition of the MAPK pathway.

\section{JIB extract plus cisplatin promoted apoptosis}

We examined whether JIB extract plus cisplatin enhanced cytotoxicity in B16/F10 cells. The morphology of B16/F10 cells was examined. As shown in Figure 5A, B16/F10 cells were detached from the dish, cell bodies were elongated, cells were floating and cell debris was generated after combination treatment (Figure 5A). Furthermore, the sub-G1 phase was examined to estimate the ratio of cell death. Results revealed that JIB extract combined with cisplatin unequivocally induced cell death, ranging from $42.76 \pm 0.49 \%$ to $87.50 \pm 1.50 \%$, in a time-dependent manner. JIB extract induced cell death, ranging from $28.60 \pm 0.55 \%$ to $41.41 \pm 0.21 \%$, and cisplatin-induced cell death, ranging from $20.22 \pm$ $0.22 \%$ to $72.05 \pm 0.30 \%$. Therefore, JIB extract synergized with cisplatin to induce about 1.2- to 2.1-fold of cell death compared with drug-only treatment in B16/F10 cells (Figure 5B). JIB extract combined with cisplatin improved cell apoptosis in B16/F10 cells, and the results showed that JIB extract synergized with cisplatin to promote cell apoptosis (Figure 5C). Hence, the mechanisms of cell apoptosis were further verified, while combination treatment was applied to B16/F10 cells. JIB extract and combination treatment were shown to reduce FAS protein expression. In addition, the expression of procaspase- 8 protein was either reduced by JIB extract only or combination treatment, suggesting that the extrinsic pathway might be activated. On the other hand, an increase in bax and decrease in bcl-2 protein expression was induced by JIB extract and combination treatment; by contrast, cisplatin did not show obvious changes in bax and bcl-2 protein expression. The ratio of bax/bcl-2 was increased, and the level of procaspase- 9 was reduced, indicating that the intrinsic pathway might be turned on after JIB extract and combination treatment. The upstream apoptotic proteins and caspase were activated, resulting in downstream procaspase- 3 and PARP reduction after JIB extract plus cisplatin treatment (Figure 5D). Therefore, JIB extract not only induced cell apoptosis but also synergized with cisplatin to promote cell apoptosis in B16/F10 cells.

\section{Discussion}

The bio-functions of JIB extract remain unclear on anti-cancer capacity; as a result, in this study, we first demonstrated the anti-melanoma activity of JIB extract. Current therapy for melanoma usually causes several side effects. For example, vemurafenib triggers the development of hand and foot syndrome [30-32], cisplatin causes nephrotoxicity and immunosuppression [33]. Additionally, drug resistance might lead to ineffective treatment. As a result, taking the abovementioned problems into consideration, JIB extract induced more cytotoxicity of B16/F10 cells than MDCK cells. This result suggested that the toxicity of JIB extract was mitigated the injury of MDCK cells. However, we utilized only B16/F10 cells 
derived from mouse strain and MDCK cells were cell lines derived from Canine strain and the more types of cell lines would need to verify the cytotoxicity of JIB extract for the future experiment.

Single drug treatment commonly impedes one or a few specific signaling pathways, which increases the risk of drug resistance. As a result, recently, combination therapy is preferred as a therapeutic strategy due to the inhibition of multiple signaling pathways preventing drug resistance, and drug

A
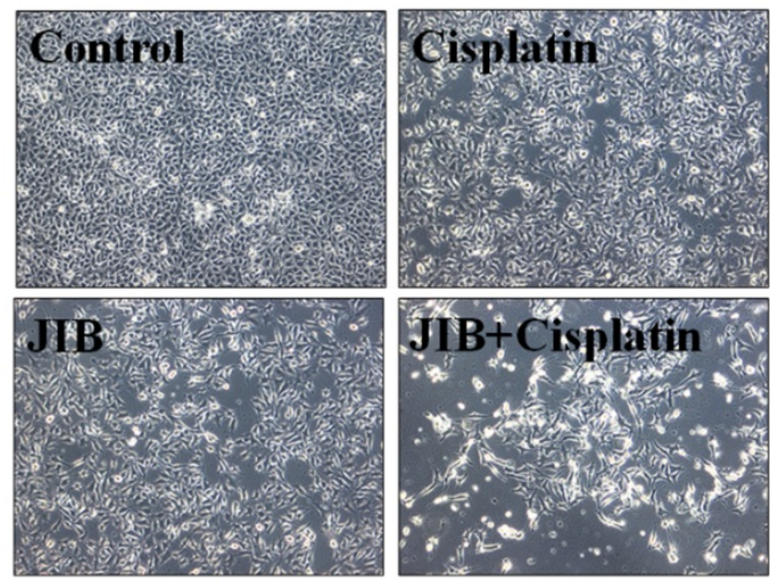

C

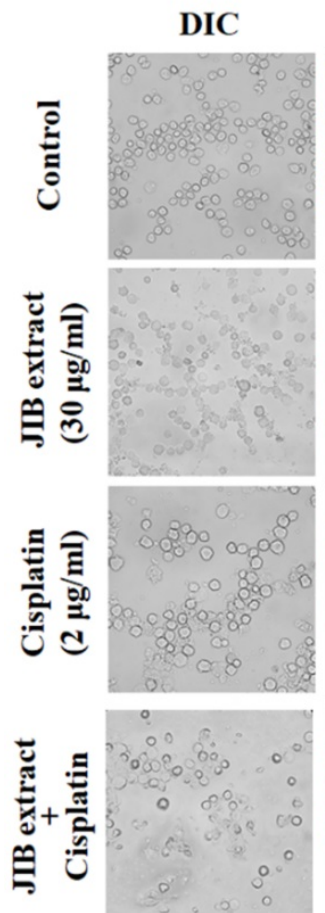

PI
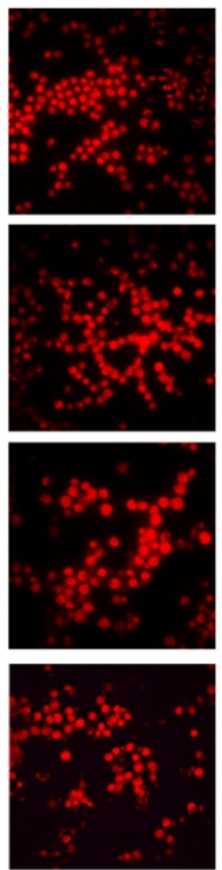

dosage is reduced to alleviate unpredictable side effects [34]. Our results indicated that JIB extract exhibited its synergistic effects with cisplatin. Furthermore, JIB extract $(30 \mu \mathrm{g} / \mathrm{ml})$ combined with cisplatin $(0.5$ and $1 \mu \mathrm{g} / \mathrm{ml})$ exhibited a synergistic effect in $48 \mathrm{hrs}$, and the CI values were 0.63 and 0.68 , respectively. The results indicated that the combinational treatment would decrease cisplatin's dose from $2 \mu \mathrm{g} / \mathrm{ml}$ to 0.5 and $1 \mu \mathrm{g} / \mathrm{ml}$ and indirectly reduce the cisplatin-induced toxicity. Besides, the

\section{B}

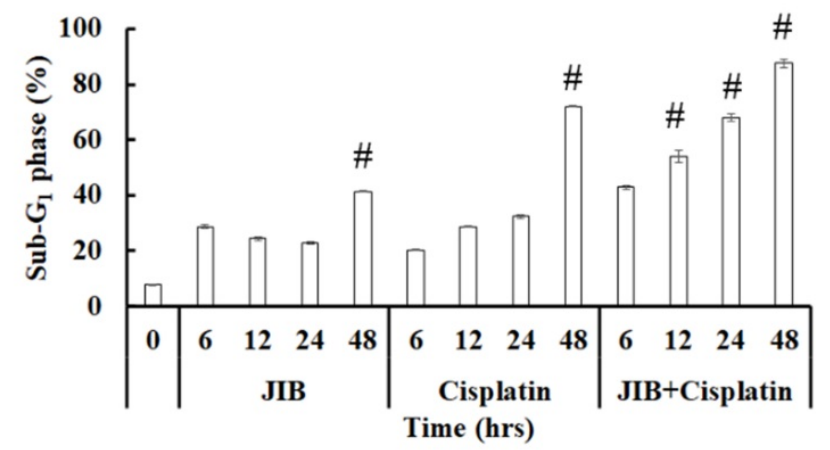

D
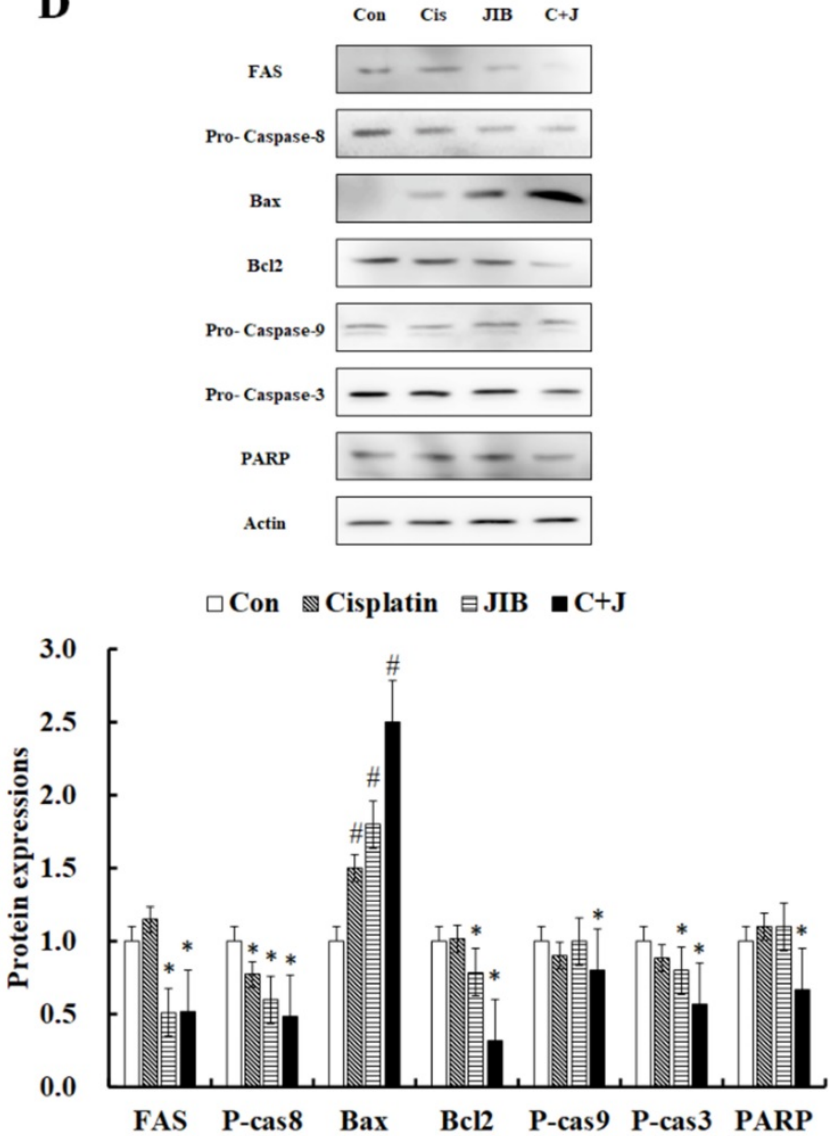

Figure 5. JIB extract synergized with cisplatin to contribute to cell apoptosis in B $16 / F 10$ cells. B16/F10 cells $(1 \times 106 /$ dish $)$ were treated with IIB extract, cisplatin, and a combination of JIB extract and cisplatin for $6,12,24$, and 48 hrs. (A) The cell morphology of B16/F10 cells after drug treatment for 48 hrs. B16/F10 cells were treated with drugs and harvested for sub-GI phase analysis by flow cytometry. (B) The sub-G। phase of B16/F10 cells after treatment. \#: It was a significant increase between untreated and treated groups $(p<0.05)$. (C) TUNEL staining of the treatments. Green: TUNEL-positive; red: PI staining as counter staining. White arrow: apoptotic bodies; red arrow: anoikis; yellow arrow: DNA fragments; blue arrow: chromatin condensation. (D) The apoptosis-related protein expression in B16/F10 cells treated with drugs for 48 hrs. $C+\mathrm{J}$ : indicated cisplatin treatment plus JIB treatment. *: It was a significant decrease between untreated and treated groups; \#: It was a significant inecrease between untreated and treated groups $(p<0.05)$. 
cytotoxicity of JIB to MDCK cells that were used as an example for kidney toxicity assay in this study was lower than cisplatin, presuming JIB extract might be less toxic to normal cells. However, there are not many studies working on the J. indica Bertol., and we will further study the new bio-functions of $J$. indica Bertol. in the future. As a result, we provide a linkage possibility of utilizing natural extract in clinical therapy or reduce side effects by combining the JIB extract and cisplatin in melanoma treatment.

The combination treatment of JIB extract and cisplatin enhanced the suppression of cell proliferation by blocking the cell cycle progression, repressing cell growth, and inhibiting cell survival via the AKT/mTOR and MAPK pathway, as well as inducing cell apoptosis through caspase activation. During the development of melanomas, the AKT/mTOR and MAPK pathways promote cell growth, proliferation, migration, apoptosis and survival, and these signaling cascades can promote melanoma metastasis results in poor prognosis [35, 36]. AKT is active during mitosis to induce mTOR/P70S6K signaling that promotes protein synthesis and cell growth [37] and can inhibit p21 expression to trigger the formation of an active cyclin D-CDK4/ 6 complex to proceed cell cycle progression [38]. Besides, ERK activation plays a critical role in several levels of cell proliferation by inhibition of CDKIs, an increment of the activity of CDKs, facilitating of cyclin D1 expression and regulation of cyclinE/CDK2 formation to enforce $\mathrm{Rb}$ phosphorylation that contributes to $G_{1} / S$ transition [27]. Literature has revealed previously that ERK and AKT activation have cooperation in inducing cyclin D1 expression. In this study, the drug alone downregulated the phosphorylated AKT/mTOR/P70S6K and ERK protein expressions. The combinational treatment synergistically reinforced the inhibition of activated AKT, mTOR, P70S6K and ERK, strengthened the reduction of phosphorylation of $\mathrm{Rb}$, the levels of cyclins A, B, D, cdk2 and cdk4 and, ultimately, enhanced the obstruction of cell cycle procced to repress cell proliferation and growth in B16/F10 cells.

Subsequently, our results revealed that JIB extract and combinational treatment both induced cell cycle arrest at $\mathrm{G}_{0} / \mathrm{G}_{1}$ phase and cisplatin administration caused $\mathrm{G}_{2} / \mathrm{M}$ phase in B16/F10 cells. The $\mathrm{Rb}$ protein is a tumor suppressor and its' phosphorylation can proceed irreversible $G_{1} / S$ transition that triggers cell proliferation [26]. Drug alone or combinational treatment inhibited the phosphorylation of $\mathrm{Rb}$ to reduce cell proliferation in B16/F10 cells. After JIB extract treatment, the level of p21 increased and downstream cyclin and cdk decreased, suggesting JIB extract could affect p21 expression to further regulate the cell cycle progression. However, JIB extract combined with cisplatin not significantly induced p21 expression. In the results, we assumed that the combination of JIB extract and cisplatin was significantly decreased the level of cyclin D, cdk2 and cdk4 contributing to $G_{0} / G_{1}$ phase arrest but not p21 expression. Or, JIB extract combined with cisplatin might exert other pathways on the mediation of cell cycle progression that deserved further investigating the detailed mechanisms in future work.

MAPK signaling plays vital roles in the regulation of cell growth, cell survival, cell proliferation, oxidant stress, and ER stress [39]. Previous results showed that the MAPK pathway in melanoma cells is highly activated and ERK, p38, and JNK proteins are overexpressed in the tumor mass of patients that are correlated with drug resistance and reduce the survival benefits of patients [40]. For instance, BRAF inhibition results in a rapid recovery of phospho-ERK (pERK) signaling result in drug resistance [41]; activation of JNK is associated with cell proliferation and shorter relapse-free period for patients with superficial spreading melanomas [42, 43]; p38 activity contribute to metastasis result in poor prognosis [44]. Numerous observations indicate a growth-promoting role of JNK in various cell types such as hepatocarcinoma cells, fibroblasts, immortalized neural stem cells and melanoma cells and have reported that active ERK indirectly facilitates the JNK activity and enforces JNK-Jun signaling to elevate cyclin D1 expression result in cell cycle progression [45]. Additionally, ERK activation is responsible for increasing the interaction between $\alpha \mathrm{V} \beta 3$ and vitronectin and stimulates p38 activity to increase melanoma cell proliferation [46, 47]. Our findings revealed that JIB extract effectively inhibited both p38, JNK and phosphorylated proteins. Furthermore, JIB extract combined with cisplatin not only significantly strengthened to reduce upstream of activated AKT and ERK proteins but also to repress downstream of activated p38 and JNK proteins. Consequently, we suggested that JIB extract potentiated cisplatin-mediated cytotoxicity through enhanced growth inhibition and increased apoptotic induction. In subsequent results, JIB extract effectively reduced the level of procaspase-8, suggesting JIB extract might activate the extrinsic apoptotic pathway. On the contrary, JIB extract increased bax/bcl2 ratio, suggesting that JIB extract might lightly induce intrinsic apoptotic apoptosis. JIB extract finally activated the caspase cascade lead to cell apoptosis. After that, JIB extract combined with cisplatin dramatically enhanced the apoptosis of B16/F10 cells 
through the increment of the extrinsic and intrinsic apoptotic pathways.

In conclusion, JIB extract combined with cisplatin had synergistic effects on the suppression of tumor cell growth and induction of apoptosis in B16/F10 cells through different molecular pathways, including AKT/mTOR, MAPK pathways, cell cycle arrest and caspase-dependent pathways. Consequently, JIB extract can be potentially used as an anti-tumor drug and adjuvant therapy for melanoma.

\section{Acknowledgments}

The authors would like to acknowledge the Instrument Center of Chung Shan Medical University for ZEISS Axio Imager A2 microscopy and BD FASCS Calibur facility.

\section{Funding}

The research was supported by National Health Research Institutes (NHRI-109BCCO-MF-202011-08) and Tri-Service General Hospital, Taiwan (TSGH-D109095, TSGH-C108-090, and ATSGH-C107-064).

\section{Availability of data and materials}

The datasets used and/or analyzed during the current study are available from the corresponding author on reasonable request.

\section{Competing Interests}

The authors have declared that no competing interest exists.

\section{References}

1. Harries M, Malvehy J, Lebbe C, Heron L, Amelio J, Szabo Z, et al. Treatment patterns of advanced malignant melanoma (stage III-IV) - A review of current standards in Europe. Eur J Cancer. 2016; 60: 179-89.

2. van Zeijl MC, van den Eertwegh AJ, Haanen JB, Wouters MW. (Neo)adjuvant systemic therapy for melanoma. Eur J Surg Oncol. 2017; 43: 534-43.

3. Florin V, Desmedt E, Vercambre-Darras S, Mortier L. Topical treatment of cutaneous metastases of malignant melanoma using combined imiquimod and 5-fluorouracil. Invest New Drugs. 2012; 30: 1641-5.

4. Kang X, Zeng Y, Liang J, Li J, Ren D, Chai L, et al. Aberrations and clinical significance of BRAF in malignant melanoma: A series of 60 cases in Chinese Uyghur. Medicine (Baltimore). 2018; 97: e9509.

5. Raje N, Chau I, Hyman DM, Ribrag V, Blay J-Y, Tabernero J, et al Vemurafenib in patients with relapsed refractory multiple myeloma harboring BRAFV600 mutations: A cohort of the histology-independent VE-BASKET Study. JCO Precis Oncol. 2018: 1-9.

6. Chapman PB, Hauschild A, Robert C, Haanen JB, Ascierto P, Larkin J, et al. Improved survival with vemurafenib in melanoma with BRAF V600E mutation. N Engl J Med. 2011; 364: 2507-16.

7. Sundar R, Cho B-C, Brahmer JR, Soo RA. Nivolumab in NSCLC: latest evidence and clinical potential. Ther Adv Med Oncol. 2015; 7: 85-96.

8. Lebbé C, Weber JS, Maio M, Neyns B, Harmankaya K, Hamid O, et al. Survival follow-up and ipilimumab retreatment of patients with advanced melanoma who received ipilimumab in prior phase II studies. Ann Oncol. 2014; 25: 2277-84

9. Hamid O, Robert C, Daud A, Hodi FS, Hwu WJ, Kefford R, et al. Five-year survival outcomes for patients with advanced melanoma treated with pembrolizumab in KEYNOTE-001. Ann Oncol. 2019; 30: 582-8.

10. Gupta A, Gomes F, Lorigan P. The role for chemotherapy in the modern management of melanoma. Melanoma Manag. 2017; 4: 125-36.

11. Siddik ZH. Cisplatin: mode of cytotoxic action and molecular basis of resistance. Oncogene. 2003; 22: 7265-79.
12. Florea AM, Busselberg D. Cisplatin as an anti-tumor drug: cellular mechanisms of activity, drug resistance and induced side effects. Cancers (Basel). 2011; 3: 1351-71.

13. Papadopoulos NE, Bedikian A, Ring S, Kim KB, Hwu WJ, Gerber DL, et al. Phase I/II study of a cisplatin-taxol-dacarbazine regimen in metastatic melanoma. Am J Clin Oncol. 2009; 32: 509-14.

14. McWilliams RR, Allred JB, Slostad JA, Katipamula R, Dronca RS, Rumilla KM, et al. NCCTG N0879 (Alliance): A randomized phase 2 cooperative group trial of carboplatin, paclitaxel, and bevacizumab \pm everolimus for metastatic melanoma. Cancer. 2018; 124: 537-45.

15. Ullah I, Subhan F, Lu Z, Chan SW, Rudd JA. Action of Bacopa monnieri to antagonize cisplatin-induced emesis in Suncus murinus (house musk shrew). J Pharmacol Sci. 2017; 133: 232-9.

16. Shahid F, Farooqui Z, Rizwan S, Abidi S, Parwez I, Khan F. Oral administration of Nigella sativa oil ameliorates the effect of cisplatin on brush border membrane enzymes, carbohydrate metabolism and antioxidant system in rat intestine. Exp Toxicol Pathol. 2017; 69: 299-306.

17. Adams RP, Chaudhary RP. Leaf essential oil of Juniperus indica Bertol. from Nepal. J Essent Oil Res. 1996; 8: 677-80.

18. Lohani H, Haider SZ, Chauhan N, Sharma M. Essential oil composition of leaves and berries of Juniperus communis and Juniperus indica from Uttarakhand Himalaya. J Med Arom Plants Sci. 2010; 32: 199-201.

19. Mahajan B, Shrestha T, Gyawali R. Antibacterial and cytotoxic activity of Juniperus indica Bertol from Nepalese Himalaya. Int J Pharm Sci Res. 2012; 3: $1104-7$

20. Singh H, Prakash A, Kalia AN, Majeed AB. Synergistic hepatoprotective potential of ethanolic extract of Solanum xanthocarpum and Juniperus communis against paracetamol and azithromycin induced liver injury in rats. J Tradit Complement Med. 2016; 6: 370-6.

21. Butani L, Afshinnik A, Johnson J, Javaheri D, Peck S, German JB, et al. Amelioration of tacrolimus-induced nephrotoxicity in rats using juniper oil. Transplantation. 2003; 76: 306-11.

22. Ju JB, Kim JS, Choi CW, Lee HK, Oh TK, Kim SC. Comparison between ethanolic and aqueous extracts from Chinese juniper berries for hypoglycaemic and hypolipidemic effects in alloxan-induced diabetic rats. J Ethnopharmacol. 2008; 115: 110-5.

23. Bais S, Abrol N, Prashar Y, Kumari R. Modulatory effect of standardised amentoflavone isolated from Juniperus communis L. against Freund's adjuvant induced arthritis in rats (histopathological and X Ray analysis). Biomed Pharmacother. 2017; 86: 381-92.

24. Lehar J, Krueger AS, Avery W, Heilbut AM, Johansen LM, Price ER, et al. Synergistic drug combinations tend to improve therapeutically relevant selectivity. Nat Biotechnol. 2009; 27: 659-66.

25. Tallarida RJ. Quantitative methods for assessing drug synergism. Genes Cancer. 2011; 2: 1003-8.

26. Giacinti C, Giordano A. RB and cell cycle progression. Oncogene. 2006; 25: 5220-7.

27. Chambard JC, Lefloch R, Pouyssegur J, Lenormand P. ERK implication in cell cycle regulation. Biochim Biophys Acta. 2007; 1773: 1299-310.

28. Lee JT, Smalley K, Brafford P, Herlyn M. p38 Represents a novel therapeutic target for advanced stage melanoma. Cancer Res. 2006; 66: 317.

29. Zhang JY, Selim MA. The role of the c-Jun N-terminal kinase signaling pathway in skin cancer. Am J Cancer Res. 2012; 2: 691-8.

30. Engel S, Luessi F, Henning B, Bittner S, Loquai C, Zipp F. Vemurafenib and cobimetinib combination therapy for BRAFV600E-mutated melanoma favors posterior reversible encephalopathy syndrome. Ann Oncol. 2019; 30: 1014-6.

31. Molnár E, Garay T, Donia M, Baranyi M, Rittler D, Berger W, et al. Long-term vemurafenib exposure induced alterations of cell phenotypes in melanoma: Increased cell migration and its association with EGFR expression. Int J Mol Sci. 2019; 20

32. Takahashi T, Abe N, Kanoh H, Banno Y, Seishima M. Synergistic effects of vemurafenib and fingolimod (FTY720) in vemurafenibresistant melanoma cell lines. Mol Med Rep. 2018; 18: 5151-8.

33. Pommergaard HC, Burcharth J, Rosenberg J, Raskov H. Topical combination of diclofenac, calcipotriol, and difluoromethylornithine has beneficial effects comparable to 5-fluorouracil for the treatment of non-melanoma skin cancer in mice. J Chemother. 2014; 26: 105-10

34. Pezzani R, Salehi B, Vitalini S, Iriti M, Zuniga FA, Sharifi-Rad J, et al. Synergistic effects of plant derivatives and conventional chemotherapeutic agents: An update on the cancer perspective. Medicina (Kaunas). 2019; 55.

35. Lemmon MA, Schlessinger J. Cell signaling by receptor tyrosine kinases. Cell. 2010; 141: 1117-34.

36. Jazirehi AR, Wenn PB, Damavand M. Therapeutic implications of targeting the PI3Kinase/AKT/mTOR signaling module in melanoma therapy. Am J Cancer Res. 2012; 2: 178-91.

37. Babchia N, Calipel A, Mouriaux F, Faussat AM, Mascarelli F. The PI3K/Akt and mTOR/P70S6K signaling pathways in human uveal melanoma cells: interaction with B-Raf/ERK. Invest Ophthalmol Vis Sci. 2010; 51: 421-9.

38. Yajima I, Kumasaka MY, Thang ND, Goto Y, Takeda K, Yamanoshita O, et al. RAS/RAF/MEK/ERK and PI3K/PTEN/AKT signaling in malignant melanoma progression and therapy. Dermatol Res Pract. 2012; 2012: 354191.

39. Krens SF, Spaink HP, Snaar-Jagalska BE. Functions of the MAPK family in vertebrate-development. FEBS Lett. 2006; 580: 4984-90.

40. Meier F, Schittek B, Busch S, Garbe C, Smalley K, Satyamoorthy K, et al. The RAS/RAF/MEK/ERK and PI3K/AKT signaling pathways present molecular 
targets for the effective treatment of advanced melanoma. Front Biosci. 2005; 10: $2986-3001$.

41. Paraiso KH, Fedorenko IV, Cantini LP, Munko AC, Hall M, Sondak VK, et al. Recovery of phospho-ERK activity allows melanoma cells to escape from BRAF inhibitor therapy. Br J Cancer. 2010; 102: 1724-30.

42. Puujalka E, Heinz M, Hoesel B, Friedl P, Schweighofer B, Wenzina J, et al. Opposing roles of JNK and p38 in lymphangiogenesis in melanoma. J Invest Dermatol. 2016; 136: 967-77.

43. Alexaki VI, Javelaud D, Mauviel A. JNK supports survival in melanoma cells by controlling cell cycle arrest and apoptosis. Pigment cell \& melanoma research. 2008; 21: 429-38.

44. Wenzina J, Holzner S, Puujalka E, Cheng PF, Forsthuber A, Neumuller K, et al. Inhibition of p38/MK2 signaling prevents vascular invasion of melanoma. J Invest Dermatol. 2020; 140: 878-90 e5.

45. Lopez-Bergami P, Huang C, Goydos JS, Yip D, Bar-Eli M, Herlyn M, et al. Rewired ERK-JNK signaling pathways in melanoma. Cancer Cell. 2007; 11: $447-60$

46. Estrada Y, Dong J, Ossowski L. Positive crosstalk between ERK and p38 in melanoma stimulates migration and in vivo proliferation. Pigment cell \& melanoma research. 2009; 22: 66-76.

47. Nebreda AR, Porras A. p38 MAP kinases: beyond the stress response. Trends Biochem Sci. 2000; 25: 257-60. 